\title{
Soot, organics, and ultrafine ash from air- and oxy-fired coal combustion
}

Myrrha E. Andersen ${ }^{1,2}$, Nabanita Modak ${ }^{2,3}$, Christopher K. Winterrowd ${ }^{4,5}$, Chun Wai Lee ${ }^{3}$, William L. Roberts ${ }^{1,6}$, Jost O.L. Wendt ${ }^{7}$, and William P. Linak ${ }^{3, *}$

${ }^{1}$ Department of Mechanical and Aerospace Engineering, North Carolina State University, Raleigh, NC 27695, USA

${ }^{2}$ Oak Ridge Institute for Science and Education, Oak Ridge, TN, 37830 USA

${ }^{3}$ National Risk Management Research Laboratory, U.S. Environmental Protection Agency, Research Triangle Park, NC 27711 USA

${ }^{4}$ ARCADIS U.S. Inc., Durham, NC 27713 USA

${ }^{5}$ Jacobs Inc., Research Triangle Park, NC 27711 USA

${ }^{6}$ Department of Mechanical Engineering, King Abdullah University of Science and Technology, Thuwal 239556900 Saudi Arabia

${ }^{7}$ Department of Chemical Engineering, University of Utah, Salt Lake City, UT 84112 USA

\author{
Prepared for presentation at: \\ $36^{\text {th }}$ International Symposium on Combustion \\ COEX, Seoul, Korea \\ July 31-August 5, 2016
}

Colloquium: 11. Formation and control of pollutants and greenhouse gases

Word count (M1):

Abstract: 269

Text: $\quad 4314$

28 References: $\quad 594$

4 Tables: $167+106+114+91 \quad 479$

3 Figures: $174+191+184 \quad 550$

Total (w/o abstract): $\quad 5937$

${ }^{*}$ Corresponding author:

William Linak

U.S. EPA, NRMRL, APPCD, E305-01

Research Triangle Park, NC 27711 USA

linak.bill@epa.gov

919-541-5792 


\begin{abstract}
Pulverized bituminous coal was burned in a $10 \mathrm{~W}$ externally heated entrained flow furnace under aircombustion and three oxy-combustion inlet oxygen conditions (28, 32, and 36\%). Experiments were designed to produce flames with practically relevant stoichiometric ratios ( $S R=1.2-1.4)$ and constant residence times (2.3s). Size-classified fly ash samples were collected, and measurements focused on the soot, elemental carbon (EC), and organic carbon $(\mathrm{OC})$ composition of the total and ultrafine $(<0.6 \mu \mathrm{m})$ fly ash. Results indicate that although the total fly ash carbon, as measured by loss on ignition, was always acceptably low ( $<2 \%)$ with all three oxycombustion conditions lower than air-combustion, the ultrafine fly ash for both air-fired and oxy-fired combustion conditions consists primarily of carbonaceous material (50-95\%). Carbonaceous components on particles $<0.6 \mu \mathrm{m}$ measured by a thermal optical method showed that large fractions $(52-93 \%)$ consisted of OC rather than EC, as expected. This observation was supported by thermogravimetric analysis indicating that for the air, $28 \%$ oxy, and $32 \%$ oxy conditions, $14-71 \%$ of this material may be OC volatilizing between 100 and $550^{\circ} \mathrm{C}$ with the remaining $29-86 \%$ being $\mathrm{EC} /$ soot. However, for the $36 \%$ oxy condition, OC may comprise over $90 \%$ of the ultrafine carbon with a much smaller EC/soot contribution. These data were interpreted by considering the effects of oxy-combustion on flame attachment, ignition delay, and soot oxidation of a bituminous coal, and the effects of these processes on $\mathrm{OC}$ and EC emissions. Flame aerodynamics and inlet oxidant composition may influence emissions of organic hazardous air pollutants (HAPs) from a bituminous coal. During oxy-coal combustion, judicious control of inlet oxygen concentration and placement may be used to minimize organic HAP and soot emissions.
\end{abstract}

Key words: oxy-coal combustion; ultrafine fly ash; loss on ignition; elemental carbon; organic carbon 


\subsection{Introduction}

Oxy-fuel combustion technology has been developed for coal-fired electric generating units (EGUs) to facilitate carbon dioxide $\left(\mathrm{CO}_{2}\right)$ capture [1]. In oxy-coal combustion, coal is burned with nearly pure oxygen $\left(\mathrm{O}_{2}\right)$ and recycled flue gas to produce emissions composed primarily of $\mathrm{CO}_{2}$ and water. The high concentrations of $\mathrm{CO}_{2}$ in the combustion chamber can affect coal devolatilization, gas diffusion, ignition, char gasification, char burnout, and the formation and oxidation of carbon monoxide [2]. This may also result in changes in the formation and behavior of pollutants, such as soot and other submicron aerosols, and the partitioning of trace species and organic hazardous air pollutants (HAPs) [3,4].

McElroy et al. [5] measured the particle size distributions of fly ash at the outlet of six coal fired boilers and determined that the mass of particles less than 2 and $1 \mu \mathrm{m}$ diameter ranged from 4 to $20 \%$ and 0.2 to $2.2 \%$ of the total mass, respectively. Markowski et al. [6] report a similar submicron mass fraction at the boiler outlet ( 1.5\%), and that reduced submicron particle collection efficiencies through an electrostatic precipitator ( 90\%) resulted in submicron particles comprising $>20 \%$ of the particle mass emissions. Thus, size-dependent collection efficiency within particle control devices causes the preferential emissions of submicron particles and species that become enriched on submicron particles. Submicron and ultrafine particles from coal combustion are typically assumed to be formed through vaporization of volatile and semivolatile metal compounds. The role of carbon often has been neglected in part because the drop tube furnace experiments used to extract data on submicron particle compositions were often operated with very high excess air. Early work by Flagan and Taylor [7], however, using a furnace (8-12kW) operated at a low, and possibly more realistic stoichiometric ratio of 1.04 indicated that carbon comprised approximately $50 \%$ of the submicron aerosol. More recent work using 30 $40 \mathrm{~kW}$ laboratory-scale coal combustors also reported high carbonaceous contents for the fine and ultrafine particles $[8,9,10,11]$. Consequently, Cho et al. [12] suggested that adverse health effects associated with ultrafine fly ash particles may be more closely associated with the carbonaceous constituents and not transition metals as was previously suspected. Morris et al. $[10,11]$ reported that oxy-coal combustion produces less 
submicron particle mass and less soot mass than did air combustion, consistent with mechanisms proposed by Shaddix and Molina [13].

Using a drop tube furnace operated at very high excess air conditions for an Illinois bituminous coal and a Powder River Basin (PRB) sub-bituminous coal, Wang et al. [14] compared the composition of combustion aerosols to (condensable) pyrolysis products of the same coals. They concluded that the condensable organic aerosols produced by combustion are most likely produced from pyrolysis precursors and consist largely of carboxylic acids/oxygenated organic compounds, rather than aromatic compounds thought to be precursors of soot. Interestingly, Fan and Brown [15] reported that LOI analysis, often used to characterize unburned carbon (char) and the extent of coal burnout, is affected by errors ( $>20 \%$ in $44 \%$ of the samples tested) caused by the presence of volatile organic compounds in the fly ash. It is unclear why these authors do not consider these compounds to be the consequence of incomplete fuel utilization.

The objectives of this research are to compare fly ash emissions of a bituminous coal for air-combustion and a typical range of oxy-combustion conditions ( 28 to $32 \% \mathrm{O}_{2}$ ) chosen to yield similar heat transfer characteristics. Size classified fly ash samples are used to characterize coal oxidation, char burnout, soot formation, and particulate-bound organic carbon. Our goals are to understand the relative contributions of carbon within the total and submicron fly ash, the distribution of elemental and organic carbon on the submicron fly ash, and the effects of oxy-combustion on theses variables. For additional insight, we also explored a third oxy-combustion condition (36\%) to determine if higher $\mathrm{O}_{2}$ partial pressures might be used to increase char oxidation and minimize soot emissions, realizing that a unique advantage of oxy-combustion is that it allows the independent control of $\mathrm{O}_{2}$ to optimize combustion efficiency within the constraints of material compatibility. 


\subsection{Materials and methods}

Experiments were performed using an entrained-flow reactor presented in Fig 1. The reactor consisted of a $5.1 \mathrm{~cm}$ inside diameter (ID), $150 \mathrm{~cm}$ long, alumina tube externally heated by a three-zone, electric furnace maintained at $1350^{\circ} \mathrm{C}$. Reactor vacuum was constant at $-0.6 \mathrm{~cm}$ water. A Utah Skyline bituminous coal, with detailed properties presented by Morris et al. $[10,11]$, was transported by air or $\mathrm{O}_{2} / \mathrm{CO}_{2}\left(21 \% \mathrm{O}_{2}\right)$ and fed through a $0.318 \mathrm{~cm} \mathrm{ID} \mathrm{stainless} \mathrm{steel} \mathrm{(SS)} \mathrm{tube} \mathrm{as} \mathrm{shown.} \mathrm{Preheated}\left(250^{\circ} \mathrm{C}\right)$ secondary oxidant was introduced around the coal and primary oxidant. Flows within the primary oxidant fuel jet were turbulent $(\mathrm{Re}=3000$ for air and 5800 for $\mathrm{O}_{2} / \mathrm{CO}_{2}$ ), expanding into laminar flow downstream ( $\mathrm{Re}=\sim 200$ or less). Particle samples were collected as shown using a SS button hook inlet faced into the flow and sized for isokinetic sampling. Gas samples were collected from the horizontal exhaust duct, conditioned to remove particles and moisture, and directed to continuous emission monitors (CEMs) measuring $\mathrm{O}_{2}, \mathrm{CO}_{2}$, carbon monoxide (CO), and nitric and nitrogen oxides ( $\mathrm{NO} / \mathrm{NO}_{\mathrm{x}}$ ). The CEMs confirmed high combustion efficiency (low $\mathrm{CO}$ ) and consistent excess $\mathrm{O}_{2}$ (stable $\mathrm{O}_{2}$ ).

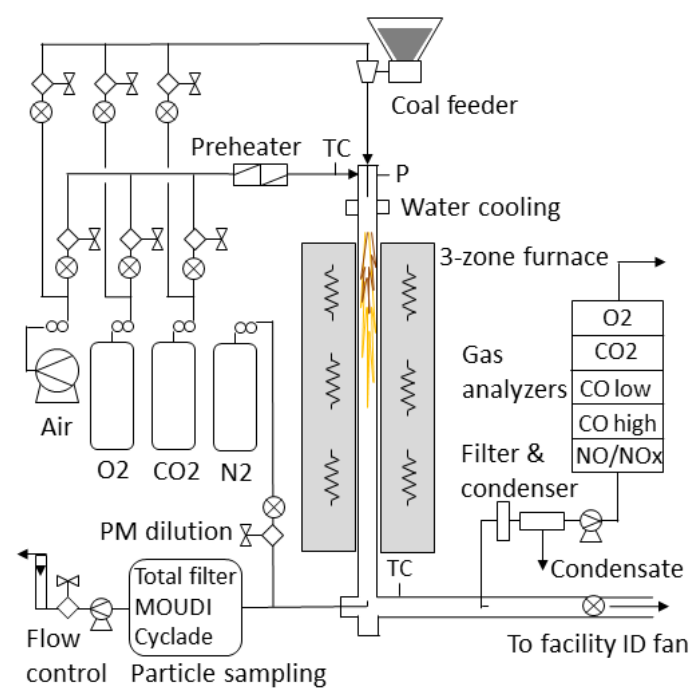

Fig. 1. Entrained flow combustor experimental facility. 
Experiments examined air-combustion and three levels of once-through oxy-combustion $(28,32$, and $36 \% \mathrm{O}_{2}$ in $\mathrm{CO}_{2}$ ), identified as AIR, OXY28, OXY32, and OXY36. This arrangement simulated dry flue gas recycling with contaminants removed. Even though inlet $\mathrm{O}_{2}$ concentrations were varied, excess $\mathrm{O}_{2}$ in the exhaust gases was held constant at 6.1\%, resulting in stoichiometric ratios ranging between 1.4 (AIR) and 1.2 (OXY36). These features distinguish the differences in the operation of this furnace from other small drop tube systems in which individual coal particles are often combusted in oxidant streams at very large stoichiometric ratios. Further, because char burnout, soot formation, and particulate bound organics were the focus of this study, fuel and oxidant flow rates were designed to maintain constant flue gas volumetric flow $(14.4 \mathrm{~L} / \mathrm{min})$ and reactor residence time $(\sim 2.3 \mathrm{~s})$ for all the experiments (see Table 1). Primary oxidant $\mathrm{O}_{2}$ concentrations were held constant at $21.0 \%$, while secondary oxidant $\mathrm{O}_{2}$ concentrations varied from 21.0 to $52.1 \%$ for the four experimental conditions. Considerable effort was made to maintain uniform coal feed rates by the choice of screw feeder (Schenck AccuRate, model 106M, Whitewater, WI), use of constant primary oxidant flow rates (7L/min), elimination of very large coal particles (100\% through 120 mesh or $125 \mu \mathrm{m})$, and pre-drying the coal to eliminate moisture $\left(105^{\circ} \mathrm{C}\right)$

Table 1

Coal and oxidant feed rates and calculated exhaust parameters. ${ }^{a}$

\begin{tabular}{|c|c|c|c|c|}
\hline & AIR & OXY28 & OXY32 & OXY36 \\
\hline Coal (g/min) & 1.28 & 1.85 & 2.15 & 2.45 \\
\hline Firing rate $(\mathrm{W})$ & 6.3 & 9.0 & 10.5 & 12.0 \\
\hline \multicolumn{5}{|l|}{ Primary flows } \\
\hline Air (L/min) & 7.00 & - & - & - \\
\hline $\mathrm{O}_{2}(\mathrm{~L} / \mathrm{min})$ & - & 1.50 & 1.50 & 1.50 \\
\hline $\mathrm{CO}_{2}(\mathrm{~L} / \mathrm{min})$ & - & 5.50 & 5.50 & 5.50 \\
\hline \multicolumn{5}{|l|}{ Secondary flows } \\
\hline $\operatorname{Air}(\mathrm{L} / \mathrm{min})$ & 6.98 & - & - & - \\
\hline $\mathrm{O}_{2}(\mathrm{~L} / \mathrm{min})$ & - & 2.34 & 2.82 & 3.30 \\
\hline $\mathrm{CO}_{2}(\mathrm{~L} / \mathrm{min})$ & - & 4.38 & 3.68 & 3.03 \\
\hline \multicolumn{5}{|l|}{ Calculated } \\
\hline SR & 1.4 & 1.3 & 1.2 & 1.2 \\
\hline Exhaust $\mathrm{O}_{2}(\%)$ & 6.1 & 6.1 & 6.1 & 6.1 \\
\hline Exhaust $\mathrm{CO}_{2}(\%)$ & 13.2 & 93.7 & 93.7 & 93.6 \\
\hline Exhaust flow (L/min) & 14.5 & 14.5 & 14.4 & 14.4 \\
\hline
\end{tabular}

${ }^{\mathrm{a}}$ Coal and oxidant feed rates were determined to result in approximately constant exhaust flow rates and reactor residence times $(2.3 \mathrm{~s})$ for all four experimental conditions. 


\section{$\underline{2.1 \text { Particle sampling and analysis }}$}

Particle samples were directed to three collection devices: a 47mm diameter quartz total filter operated at $28 \mathrm{~L} / \mathrm{min}$, a Cyclade cascade cyclone, and a Micro Orifice Uniform Deposition Impactor (MOUDI). The Cyclade, a five-stage cyclone designed to operate at $28 \mathrm{~L} / \mathrm{min}$ with $50 \%$ aerodynamic cutoff diameters $\left(\mathrm{Dp}_{50}\right)$ of $7.5,3.5$, $2.7,1.1$, and $0.57 \mu \mathrm{m}$, was followed by a borosilicate glass fiber thimble filter to collect particles $<0.57 \mu \mathrm{m}$. The MOUDI, a nine-stage atmospheric pressure cascade impactor designed to operate at $30 \mathrm{~L} / \mathrm{min}$ with $\mathrm{Dp}_{50}$ of 18.0 , $10.0,5.6,3.2,1.8,1.0,0.56,0.32$, and $0.18 \mu \mathrm{m}$ had its last two stages omitted so that particles $<0.56 \mu \mathrm{m}$ could be collected by a $47 \mathrm{~mm}$ diameter quartz after-filter. With $D p_{50}$ of 0.57 and $0.56 \mu \mathrm{m}$, respectively, the Cyclade thimble filter and MOUDI after-filter both collect similar accumulation mode aerosol formed via vaporization followed by nucleation, coagulation/agglomeration, and condensation, while excluding most particles formed via fragmentation and comminution processes. With large surface area, the thimble filters could collect sufficient samples for accurate gravimetric analysis. However, the MOUDI after-filter allowed only small masses, sometimes unsuitable for accurate gravimetric analysis, to be collected before plugging occurred. The $10 \mathrm{~L} / \mathrm{min}$ particle samples were diluted $\sim 2: 1$ with dry $\mathrm{N}_{2}$. After stable operation was established, particle samples were collected for long periods of time, sometimes compositing samples over several days to collect sufficient material for analysis. Thus, the data presented represent many replications of the same experimental conditions. Duct temperatures at the sampling probe ranged from 316 to $365^{\circ} \mathrm{C}$, and sample temperatures after dilution ranged from 122 to $126^{\circ} \mathrm{C}$. These sample temperatures allowed condensation of semivolatile organics but avoided the acid dew point.

Bulk particle samples recovered from the total filter and the Cyclade stages were analyzed in an oxidizing environment by thermogravimetric analysis (TGA) to determine loss on ignition (LOI) following ASTM method D7348-13 [16]. LOI values for the Cyclade thimble filters were determined in a similar manner. The MOUDI after-filters were used to determine OC and EC and then used to attempt to quantify extractable organic matter (EOM). For OC-EC analysis, a $1.5 \mathrm{~cm}^{2}$ rectangular punch was taken from each after-filter and analyzed 
according to NIOSH method 5040 [17] using a Sunset Laboratory OC-EC analyzer (Tigard, OR). The method uses stepped heating under sequential reducing and oxidizing environments to vaporize mass from the sample. Once vaporized, the carbon is oxidized to $\mathrm{CO}_{2}$, reduced to methane, and quantified by flame ionization detection. The OC-EC analyzer measures carbon mass sequentially removed from the after-filter sample directly and sample weights were not required. Following OC-EC analysis, the remaining after-filter was divided in two, and each half extracted using either dichloromethane (DCM) or methanol (MeOH) solvents for EOM following the method described by DeMarini et al. [18]. For EOM determinations, accurate sample weights are necessary, and these results are sometimes affected by our ability to quantify sample mass. Further, material on the missing $1.5 \mathrm{~cm}^{2}$ punch was included mathematically by assuming uniform distribution of sample mass over the after-filter surface. DCM and MeOH solvents were chosen for their ability to extract moderately polar and highly polar organic species, respectively. Method blanks using DCM and MeOH solvents produced negligible EOM weights.

\subsection{Experimental results}

\subsection{Combustor characterization}

Table 2 presents average gas exhaust measurements for $\mathrm{O}_{2}, \mathrm{CO}_{2}, \mathrm{CO}, \mathrm{NO}$, and $\mathrm{NO}_{\mathrm{x}}$ for the four combustion conditions examined. Flue gas flow rates were held constant by adjusting coal feed rates (Table 1). The transport primary oxidant flow rate, velocity, and $\mathrm{O}_{2}$ concentration $(21 \%)$ were held constant for all experiments. These conditions required modest variations in secondary oxidant flow rates and corresponding increase of secondary $\mathrm{O}_{2}$ concentrations shown on Table 1. Measured $\mathrm{O}_{2}$ and $\mathrm{CO}_{2}$ concentrations agree reasonably well with a mass balance showing close to $93 \%$ theoretical exhaust $\mathrm{CO}_{2}$ concentration and demonstrating that significant air leakage was not an issue. Average CO concentrations below $25 \mathrm{ppm}$ were measured for all four experiments, suggesting efficient combustion. Interestingly, OXY28 exhibited the highest average $\mathrm{CO}$ emissions with the noisiest CO concentration traces. In contrast, OXY36 exhibited notably lower average $\mathrm{CO}$ emissions and very stable $\mathrm{CO}$ concentration traces. $\mathrm{NO}_{\mathrm{x}}$ emissions on a mass/unit energy basis (Table 2) are consistent with elimination of thermal NO for the oxy-combustion experiments, although it should 
be noted that the lack of recycled flue gas does not allow reburning to further decrease $\mathrm{NO}_{\mathrm{x}}$ concentrations. The decrease with increasing inlet $\mathrm{O}_{2}$ concentration is less clear and is most likely due to aerodynamic changes caused by the higher coal flow rates.

\section{Table 2}

Averaged measured gas phase emissions. ${ }^{a}$

\begin{tabular}{lcccc} 
Emission & AIR & OXY28 & OXY32 & OXY36 \\
\hline $\mathrm{O}_{2}(\%)$ & $6.5 \pm 0.4$ & $6.6 \pm 0.1$ & $6.5 \pm 0.1$ & $6.1 \pm 0.2$ \\
$\mathrm{CO}_{2}(\%)$ & $12.9 \pm 0.4$ & $92.4 \pm 2.0$ & $90.9 \pm 0.2$ & $92.4 \pm 0.5$ \\
$\mathrm{CO}(\mathrm{ppm})$ & $11.1 \pm 4.8$ & $21.8 \pm 0.4$ & $20.4 \pm 3.9$ & $12.6 \pm 0.9$ \\
$\mathrm{NO}(\mathrm{ppm})$ & $741.7 \pm 43.9$ & $809.4 \pm 11.0$ & $758.9 \pm 23.6$ & $823.2 \pm 53.8$ \\
$\mathrm{NO}_{\mathrm{x}}(\mathrm{ppm})$ & $807.8 \pm 35.3$ & $844.7 \pm 5.7$ & $786.1 \pm 26.6$ & $843.9 \pm 46.1$ \\
$\mathrm{NO}_{\mathrm{x}}(\mathrm{g} / \mathrm{MJ})^{\mathrm{b}}$ & 0.599 & 0.433 & 0.345 & 0.324 \\
Fuel N conv. (\%) & - & 27.2 & 21.6 & 20.4 \\
\hline
\end{tabular}

a \pm standard deviation.

${ }^{b} \mathrm{NO}_{x}$ emission converted to equivalent $\mathrm{NO}_{2}$.

\section{$\underline{3.2 \text { Carbon and ultra-fine particles }}$}

Loss on ignition (LOI) results are presented in Table 3. Although LOI is considered the standard method for determining the carbon content of fly ash from coal-fired boilers [19], it may also include contributions from volatile metals and metal decomposition [15]. Average LOI values and standard deviations are presented for total filter samples (bulk fly ash), five Cyclade stages, and Cyclade thimble filter samples $(<0.57 \mu m)$. The number of replicate samples are indicated in parenthesis. The total filter results, presented in Fig $2 \mathrm{a}$, indicate very low LOI values decreasing from approximately 2 to $0.2 \%$ as $\mathrm{O}_{2}$ concentration increases from AIR to OXY36 indicating efficient combustion. Note, however, that total filter ash LOI does not track CO concentrations in the exhaust (Table 2). The improved carbon burnout with increasing $\mathrm{O}_{2}$ concentration may be due in part to the increased char combustion temperature and reduced char burnout time as suggested by Murphy and Shaddix [20].

In contrast to these low LOI values for the bulk ash, Table 3 shows that as the sampled particle size decreases, the LOI of each sample greatly increases, suggesting that the ultrafine particles are predominantly 
carbonaceous. The ultrafine particles on the thimble filter $(<0.57 \mu \mathrm{m})$ and MOUDI after filter $(<0.56 \mu \mathrm{m})$ were visibly black, while those collected on the total filter and in Cyclade stage $1(>7.5 \mu \mathrm{m})$ were tan. The Cyclade samples became increasingly dark with decreasing particle size. LOI values for the thimble filters $(<0.57 \mu \mathrm{m})$ are shown on Fig $2 \mathrm{~b}$ and range from $59.9 \%$ to $92.2 \%$. Note that on switching from AIR to OXY the LOI initially increased and then decreased as the $\mathrm{O}_{2}$ content in the secondary oxidant increased. This is a different dependence on $\mathrm{O}_{2}$ than is exhibited by the total fly ash (Fig. 2a). Interestingly, the thimble filter LOI does track the exhaust $\mathrm{CO}$ concentration while the total filter LOI does not. These results imply that the maximum for the ultrafine carbon originates from a real mechanism, not an artifact, and that further analysis, described below, may help reveal these potential mechanisms.

\section{Table 3}

Loss on ignition values for bulk fly ash and six Cyclade size-classified fly ash fractions. ${ }^{a}$

\begin{tabular}{lcccc}
$\begin{array}{l}\text { Aerodynamic } \\
\text { Diameters }\end{array}$ & AIR & OXY28 & OXY32 & OXY36 \\
\hline Bulk fly ash & $2.06 \pm 1.40(4)$ & $1.18 \pm 1.36(3)$ & $0.52 \pm 0.59(3)$ & $0.22 \pm 0.17(3)$ \\
\hline $1>7.5 \mu \mathrm{m}$ & $2.14 \pm 0.19(3)$ & $1.98 \pm 2.00(2)$ & $3.60 \pm 3.10(2)$ & 1.30 \\
$23.5-7.5 \mu \mathrm{m}$ & $2.80 \pm 0.15(3)$ & $2.71 \pm 2.24(2)$ & $7.68 \pm 7.55(2)$ & 3.29 \\
$32.7-3.5 \mu \mathrm{m}$ & $8.16 \pm 2.69(3)$ & $8.51 \pm 8.37(2)$ & $14.24 \pm 3.15(2)$ & 5.74 \\
$41.1-2.7 \mu \mathrm{m}$ & 17.95 & 22.45 & 52.47 & 15.14 \\
$50.57-1.1 \mu \mathrm{m}$ & 45.20 & $\mathrm{n} / \mathrm{a}^{\mathrm{b}}$ & $\mathrm{n} / \mathrm{a}$ & $\mathrm{n} / \mathrm{a}$ \\
$<0.57 \mu \mathrm{m}$ & $76.92 \pm 4.26(3)$ & 92.20 & $85.60 \pm 6.56(2)$ & 59.92
\end{tabular}

\footnotetext{
${ }^{a}$ Number of replicate samples indicated in parenthesis. Replicate samples for stages 4 and 5 were combined. ${ }_{\mathrm{b}}^{\mathrm{b}}$ /a samples with insufficient mass to perform LOI analysis.
}

Table 3 also presents LOI results for five size-classified Cyclade samples. Mass loss measured from samples collected in stages 1 and $2(>3.5 \mu \mathrm{m})$ is generally similar to the mass loss measured for the bulk fly ash indicating that large particles dominate the fly ash. As particle size decreases, LOI values increase. Compared to large ash particles, smaller particles exhibit relatively larger number concentrations and surface areas so that preferential agglomeration of carbon rich ultrafine particles and condensation of organic species on these particles may account for the composition differences compared to larger particles. Finally, particles $<0.3 \mu \mathrm{m}$ are 
dominated by gas to particle conversion processes, particle nucleation, and particle growth via coagulation, agglomeration and condensation. In contrast to the thimble filter samples $(<0.57 \mu \mathrm{m})$, for which accumulation mode samples with sufficient (carbon) mass for LOI analysis could be collected, replicate samples from Cyclade stages 4 (1.1-2.7um) and $5(0.57-1.1 \mu \mathrm{m})$ were either combined to provide sufficient mass or too small for LOI analysis (see Table 3). This observation corresponds to the known characteristics of coal fly ash particle size distributions $[6,21]$.

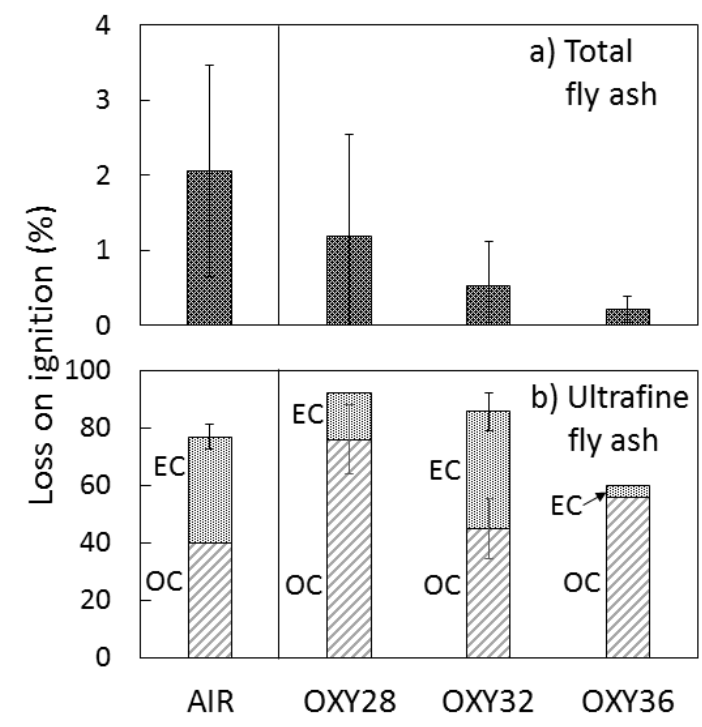

Fig. 2. Loss on ignition for (a) total fly ash, and (b) ultrafine fly ash.

\subsection{Organic carbon (OC) and elemental carbon (EC)}

Carbonaceous aerosols in the atmosphere are divided into OC and EC. Although OC and EC are defined by the thermal-optical analytical method used $[22,23]$, one may loosely view OC as volatilizable organic condensates containing carbon, hydrogen, oxygen and other elements, whereas EC consists of refractory "soot like" carbon with few or no other elements. Table 4 presents the OC/TC (total carbon, TC=OC+EC) and EOM (solubility) results for the MOUDI after-filters $(<0.56 \mu \mathrm{m})$. Average values with standard deviations of replicate samples when available are indicated. The data yield the surprising conclusion that OC represents a large fraction (50 to $90 \%$ ) of the TC in these ultrafine carbonaceous samples. However, the EOM results are less 
definitive and are likely affected by the fact that we were using half samples already punched for OC-EC analysis with low initial weights. While gas chromatography/mass spectroscopy was unable to qualitatively or quantitatively identify specific species due to very small sample sizes, the data suggest low organic mass soluble in DCM, but higher fractions (excepting AIR) soluble in $\mathrm{MeOH}$. Based on color, the DCM extracts were predominantly clear, while the $\mathrm{MeOH}$ extracts (including AIR) were all brown to black. Although not entirely consistent, we believe that the data suggest that a significant fraction of the ultrafine particle mass may be $\mathrm{MeOH}$ extractable (possibly indicating the presence of highly polar organic compounds), but a smaller fraction is DCM extractable (possibly indicating the presence of small amounts of $\mathrm{PAH}$-like compounds). Large $\mathrm{MeOH}$ extractable mass suggests the presence of highly polar organic compounds [18], and is consistent with the observations by Zhang et al. [24] and Wang et al. [14] regarding the presence of oxygenated compounds such as carboxylic acids in the ultrafine fly ash. The DCM EOM also decreases from OXY28 to OXY32 to OXY36, consistent with the effects of increasing levels of oxy-combustion to enhance soot oxidation.

Table 4

Percent organic carbon and percent extractable organic matter of ultrafine fly ash $(<0.56 \mu \mathrm{m}){ }^{a}$

\begin{tabular}{lcccc} 
& AIR & OXY28 & OXY32 & OXY36 \\
\hline OC/TC (\%) & 52.0 & $82.5 \pm 12.0(2)$ & $52.5 \pm 10.6(2)$ & 93.0 \\
\hline EOM in DCM (\%) & 2.4 & 6.8 & 3.0 & 0.2 \\
EOM in MeOH (\%) & 2.8 & 22.0 & 23.0 & $>100^{\mathrm{b}}$ \\
\hline Normalized TGA (\%) & 39.0 & 71.0 & 13.9 & 92.5 \\
\hline
\end{tabular}

${ }^{\mathrm{a}}$ Number of replicate samples indicated in parenthesis.

${ }^{\mathrm{b}}$ EOM mass recovery $>100 \%$.

${ }^{\mathrm{C}} \mathrm{TGA}$ weight loss from $100-550^{\circ} \mathrm{C}$, normalized to total weight loss from $100-700^{\circ} \mathrm{C}$.

To independently verify these OC-EC results, we compared the LOI weight loss profiles of the ultrafine coal ash samples to the LOI weight loss profiles of carbon black, and two widely shared reference diesel emission particulates (DEPs), National Institute of Standards and Technology Standard Reference Material (NIST SRM) 2975 (N-DEP) and an automotive DEP (A-DEP) [25]. Stevens et al. [26] present OC-EC and EOM data for these DEP samples. Carbon black can be considered as essentially $100 \%$ EC, N-DEP has low OC, high EC, with OC/TC and EOM values of 0.07 and $1.5 \%$, respectively, and A-DEP has high OC, low EC, with OC/TC and EOM values of 
0.85 and $68.6 \%$, respectively [26]. TGA profiles for these three materials are presented in Fig 3a, and indicate that even though all three of these samples are almost entirely carbonaceous, they yield very different TGA profiles, which can be related to the relative amounts of organic and elemental carbon present. If we choose $550^{\circ} \mathrm{C}$ as the transition temperature between $\mathrm{OC}$ and $\mathrm{EC}$, we note that the carbon black, N-DEP, and A-DEP samples have lost $0,23.1$, and $80.6 \%$ of their mass at that temperature, respectively. The corresponding measured OC/TC values were 7 and $85 \%$ for N-DEP and A-DEP, respectively, as reported by Stevens et al. [26]. Although the chosen temperature of $550^{\circ} \mathrm{C}$ is somewhat arbitrary, the TGA profiles can be semi-quantitatively related to the measured $\mathrm{OC} / \mathrm{TC}$ ratio.

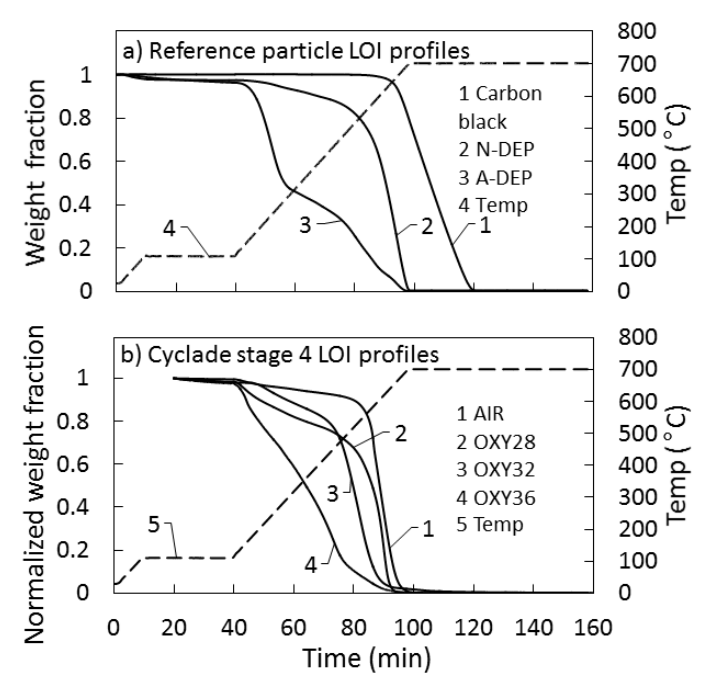

Fig. 3. Thermogravimetric profiles for (a) three prototype carbon particles, and (b) four Cyclade stage 4 samples.

Fig 3b presents TGA profiles for the air-coal and three oxy-coal experimental conditions examined. These profiles are for the Cyclade stage 4 samples (1.1-2.7um) that contained some, but not large amounts of carbonaceous material (see Table 3). We examine stage 4 samples because we could not collect sufficient mass on stage $5(0.57-1.1 \mathrm{um})$ and because LOI analysis of the thimble filters $(<0.57 \mathrm{um})$ did not produce mass loss profiles. On the assumption that the carbon partitioning to the stage 4 samples is similar to the carbon collected on the thimble filters and MOUDI after-filters as far as OC and EC are concerned, the data should provide useful 
corroboration of the OC data reported above. The weight loss profiles presented in Fig. $3 \mathrm{~b}$ have been normalized relative to the ultimate weight loss, so that weight lost between 100 and $700^{\circ} \mathrm{C}$ is depicted as weight fractions between 1 and 0 . Key observations are that the carbonaceous material TGA profiles differ measurably from that of the carbon black, suggesting that they all represent the release of various amounts of OC. Using an OC-EC transition temperature of $550^{\circ} \mathrm{C}$, roughly consistent with the $\mathrm{OC}$-EC transitions of the three prototype

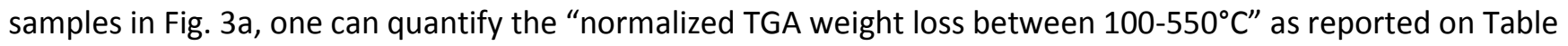

4. Comparison with the measured OC/TC values is fair (excepting OXY32), but the trends are well represented. These measurements obtained by a different analytical approach support the direct OC/TC measurements reported above and indicate once more, that $\mathrm{OC}$ can be a very significant fraction of the carbonaceous material associated with the fly ash. From this observation, one can infer not only that major portions of the ultrafine particle mass consist primarily of carbonaceous material, but also that these portions consist largely of OC rather than EC.

\subsection{Discussion}

The important result from Fig. 2 is that inorganic ash elements may actually comprise a relatively smaller fraction of the ultrafine ash than previously has been appreciated. This is in agreement with some studies $[7,10,11,27,28]$ who have reported high fractions of submicron carbon or soot, as opposed to unburned char, in ash from 10-100 kW laboratory combustors and field units, but in disagreement with studies using drop tube furnaces at very high stoichiometric ratios. The preponderance of carbon in the ultrafine fraction of coal ash is important and requires further study to understand how this conclusion depends on unit size, coal type, and burner configuration.

That so much of the carbon in the ultrafine ash consists of $O C$ rather than $E C$ is surprising but in agreement with the conclusions of Zhang et al. [24], who focused on particle mass $<2.5 \mu \mathrm{m}$ from Chinese coals. Mechanisms of formation of OC are quite different from the mechanisms forming EC. OC is most likely the 
result of gas-phase hydrocarbons evolving from the coal prior to ignition and then bypassing the flame front to be slowly or partially oxidized in the boiler, and depending on vapor pressure, nucleating homogeneously or heterogeneously condensing on existing EC or inorganic particles as temperatures cool. EC, on the other hand, is most likely formed through a soot formation mechanism where high molecular weight (PAH-rich) tars are formed, nucleate, coagulate, anneal, and agglomerate into chain-like structures before passing through the flame front where the vast majority are oxidized. One key difference is that $\mathrm{OC}$ is evolved early and can be conveyed to the exhaust without ever passing through a flame. Precursors to EC are formed late, and they pass through the flame front where the majority are oxidized. This suggests that the relative amounts of OC and EC vary significantly with location and the stage of volatile or char combustion. While this would be difficult to measure for these drop tube experiments, a study by Mitchell et al. [29] measured temporal changes in EC/TC in a small fixed bed combustor (a domestic stove) burning biomass and coal fuels, and found large EC/TC variations with time as combustion proceeded through distinct ignition, flaming, and smoldering phases. One might well wonder whether residual organic HAPs from coal combustion can be represented by OC in the ultrafine particle mass, and whether they arise from coal flame detachment problems. Flame detachment issues may also provide insight into the occurrence of maxima in LOI and OC concentrations in the ultrafine ash as we switch from AIR to OXY28, OXY32 and OXY36, as explained below.

The maximum of carbon in ultrafine fly ash at OXY28 may be explained through the competing effects of oxy-firing tending to delay ignition of volatiles [30,31], allowing increased OC to bypass the flame, and increased $\mathrm{O}_{2}$ concentration tending to increase rates of coal particle ignition [31]. Molina and Shaddix [31] also suggest that particle ignition and devolatilization properties in a mixture of $30 \% \mathrm{O}_{2}$ in $\mathrm{CO}_{2}$ are very similar to air. In our experiments, OXY32 $\left(32 \% \mathrm{O}_{2}\right.$ in $\left.\mathrm{CO}_{2}\right)$ led to similar carbonaceous compositions and OC/TC ratios as AIR, while OXY28 and OXY36 were different. This observation suggests that the composition trends of LOI, OC and EC of the ultrafine ash observed by us are also controlled by the competing processes of ignition delayed by the presence of increased $\mathrm{CO}_{2}$ and the reactivity promoted by increased $\mathrm{O}_{2}$ especially apparent for the OC, which, 
according to the discussion above, would be minimized with the minimum flame detachment distance. Wang et al. [14] observed that aerosol emissions from combustion of an Illinois bituminous coal contained significantly more oxygenated compounds than aerosol from a PRB coal, despite the much lower $\mathrm{O}_{2}$ content of the Illinois coal. Partial oxidation of less reactive volatiles generated by the Illinois coal was attributed to higher levels of oxygenated compounds in the aerosols. These observations are consistent with the trends of LOI, OC, and EC of the ultrafine ash seen here, that are resulting from competing processes of ignition delayed by $\mathrm{CO}_{2}$ and the reactivity promoted by increased $\mathrm{O}_{2}$. These observations also suggest that $\mathrm{EC}$ and $\mathrm{OC}$ emissions from subbituminous and bituminous coals may be different, and that control of $\mathrm{O}_{2}$ concentration and placement during oxy-coal combustion might be used to minimize organic HAPs and soot. Models that combine devolatilization, ignition, soot formation and oxidation within coal flames are needed to predict OC and EC emissions, and the development of such model represent an opportunity and challenge for oxy-coal combustion [32].

\subsection{Conclusions}

LOI, OC, and EC analyses of size classified fly ash samples from air- and oxy-combustion of a bituminous coal in a 10W entrained flow furnace operated at realistic stoichiometric ratios indicate that although the total fly ash carbon was always acceptably low $(<2 \%)$, the ultrafine fly ash $(<0.6 u m)$ from both air- and oxycombustion consists largely of carbonaceous material. This observation is contrary to many previous studies that focused primarily on the vaporization, nucleation, and growth of volatile and semivolatile metals. The effect of oxy-combustion conditions is first to increase the ultrafine carbonaceous material and then to decrease the ultrafine carbonaceous material, as the percentage of inlet $\mathrm{O}_{2}$ is increased and $\mathrm{CO}_{2}$ decreased. Much of the LOI present in the ultrafine ash consists of OC, believed to contain significant amounts of oxygenated hydrocarbons. During oxy-coal combustion, changes in both the ultrafine OC and the EC can be explained by the competing effects of $\mathrm{CO}_{2}$ and $\mathrm{O}_{2}$ on the flame stand-off distance and soot oxidation, respectively. CO does appear to track the observed LOI trends of the ultrafine fly ash $(<0.6 \mu \mathrm{m})$. However, CO does not follow the LOI trends of the bulk ash. Comparison of the OC data between air-and oxy-combustion suggest that any factor 
that affects flame attachment and delayed ignition may also affect the emissions of hazardous organic air pollutants. Coal type may be an important factor for organic HAP emissions, requiring further study. These results suggest that the independent control of $\mathrm{O}_{2}$ concentration offered by oxy-combustion may also allow the control of OC, EC, soot, and organic HAPs.

\section{Acknowledgements/Disclaimer}

Portions of this work were sponsored under the EPA/DOE interagency agreement DW-89-92298301 with Oak Ridge Institute for Science and Education (ORISE) and EPA contract EP-C-09-027 with ARCADIS U.S., Inc. The authors are grateful to Daniel Janek, Aaron DeBlois, James Gustafson, Garrett Wiley, Mike Tufts, Bill Preston, Dean Smith, and Bakul Patel for their assistance in the construction and operation of the experimental combustor, and sample collection and analyses. The research described in this article has been reviewed by the U.S. EPA National Risk Management Research Laboratory and approved for publication. The contents of this article should not be construed to represent Agency policy nor does mention of trade names or commercial products constitute endorsement or recommendation for use. 


\section{References}

[1] T.F. Wall, Proc. Combust. Inst., 31 (2007) 31-47.

[2] C.R. Shaddix, A. Molina, Effect of $\mathrm{CO}_{2}$ on coal char combustion rates in oxy-fuel applications, $24^{\text {th }}$ Intl. Pittsburgh Coal Conf., Sept. 10-14, 2007.

[3] J. Koornneef, A. Ramirez, T. van Harmelen, A. van Horssen, W. Turkenburg, A. Faaij, Atmos. Environ., 44 (2010) 1369-1385.

[4] C.L. Senior, W. Morris, T.A. Lewandowski, J. Air Waste Manage. Assoc., 63(7) (2013) 832-843.

[5] M.W. McElroy, R.C. Carr, D.S. Ensor, G.R. Markowski, Science, 215 (1982) 13-19.

[6] G.R. Markowski, D.S. Ensor, R.G. Hooper, R.C. Carr, Environ. Sci. Technol., 14 (1980) 1400-1402.

[7] R.C. Flagan, D.D. Taylor, Laboratory studies of submicron particles from coal combustion, $18^{\text {th }}$ Symp. (Intl.) Combust., (1981) 1227-1237.

[8] M.I. Gilmour, S. O’Connor, C.A.J. Dick, C.A. Miller, W.P. Linak, J. Air \& Waste Manage. Assoc., 54 (2004) 286-295.

[9] W.P. Linak, J.-I. Yoo, S.J. Wasson, W. Zhu, J.O.L. Wendt, F.E. Huggins, Y. Chen, N. Shah, G.P. Huffman, M.I. Gilmour, Proc. Combust. Inst., 31 (2007) 1929-1937.

[10] W.J. Morris, D. Yu, J.O.L. Wendt, Proc. Combust. Inst., 33 (2011) 3415-3421. 
[11] W.J. Morris, D. Yu, J.O.L. Wendt, Proc. Combust. Inst., 34 (2013) 3453-3461.

[12] S.-H. Cho, J.-I. Yoo, A.T. Turley, C.A. Miller, W.P. Linak, J.O.L. Wendt, F.E. Huggins, M.I. Gilmour, Proc. Combust. Inst., 32 (2009) 2717-2725.

[13] C.R. Shaddix, A. Molina, Proc. Combust. Inst. 32(2) (2009) 2091-2098.

[14] X. Wang, E. Cotter, K.N. lyer, J. Fang, B.J. Williams, P. Biswas, Proc. Combust. Inst., 35(2) (2015) 2347-2354.

[15] M. Fan, R.C. Brown, Energy Fuels, 15, (2001) 1414-1417.

[16] ASTM method D7348-13, Standard test methods for loss on ignition (LOI) of solid combustion residues, available at: http://www.astm.org/Standards/D7348.htm, accessed April 2015.

[17] M.E. Birch, R.A. Cary, Aerosol Sci. Technol. 25 (1996) 221-241.

[18] D. DeMarini, L.R. Brooks, S.H. Warren, T. Kobayashi, M.I. Gilmour, P. Singh, Environ. Health Perspect., $112(8)(2004) 814-819$.

[19] K. Styszko-Grochowiak, J. Golas, H. Jankowski, S. Kozinski, Fuel, 83 (2004) 1847-1853.

[20] J.J. Murphy, C.R. Shaddix, Combust. Flame, 144 (2006) 710-729. 
[21] W.P. Linak, C.A. Miller, W.S. Seames, J.O.L. Wendt, T. Ishinomori, Y. Endo, S. Miyamae, Proc. Combust. Inst., 29 (2002) 441-447.

[22] J.C. Chow, J.G. Watson, D. Crow, D.H. Lowenthal, T. Merrifield, Aerosol Sci. Technol., 34, (2001) 23-34.

[23] T.L.B. Yelverton, M.D. Hays, B.K. Gullett, W.P. Linak, Environ. Engineer. Sci., 31(4) (2014) 209-215.

[24] Y. Zhang, J.J. Schauer, Y. Zhang, L. Zeng, Y. Wei, Y. Liu, M. Shao, Environ. Sci. Technol., 42 (2008) 50685073.

[25] T. Kobayashi, T. Ito, Fund. Appl. Toxicol., 27 (1995) 195-202.

[26] T. Stevens, S.-H. Cho, W.P. Linak, M.I. Gilmour, Toxicol. Sci., 107(2) (2009) 522-534.

[27] J.M. Veranth, D.W. Pershing, A.F. Sarofim, J.E. Shield, Sources of unburned carbon in the fly ash produced from low- $\mathrm{NO}_{x}$ pulverized coal combustion, $27^{\text {th }}$ Symp. (Intl.) Combust., The Combust. Inst., Pittsburgh, (1998) 1737-1744.

[28] J.M. Veranth, T.H. Fletcher, D.W. Pershing, A.F. Sarofim, Fuel, 79 (2000) 1067-1075.

[29] E.J.S. Mitchell, A.R., Lea-Langton, J.M. Jones, A. Williams, P. Layden, R. Johnson, Fuel Process. Technol., 142 (2016) 115-123.

[30] B.J.P. Buhre, L.K. Elliott, C.D. Sheng, R.P. Gupta, T.F. Wall, Prog. Energy Combust. Sci., 31 (2005) 283-307. 
[31] A. Molina, C.R. Shaddix, Proc. Combust. Inst., 31, (2007) 1905-1912.

[32] P. Edge, M. Gharebaghi, R. Irons, R. Porter, R.T.J. Porter, M. Pourkashanian, D. Smith, P. Stephenson, A. Williams, Chem. Eng. Res. Des., 89 (2011) 1470-1493. 


\section{List of figures}

Fig. 1. Entrained flow combustor experimental facility.

Fig. 2. Loss on ignition for (a) total fly ash, and (b) ultrafine fly ash.

Fig. 3. Thermogravimetric profiles for (a) three prototype carbon particles, and (b) four Cyclade stage 4 samples. 